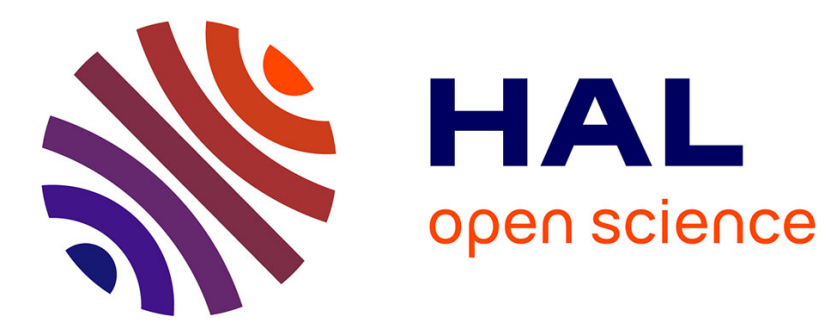

\title{
Kurchatov synchrotron radiation source
}

V. Stankevitch

\section{- To cite this version:}

V. Stankevitch. Kurchatov synchrotron radiation source. Journal de Physique IV Proceedings, 1994, 04 (C9), pp.C9-377-C9-381. 10.1051/jp4:1994963 . jpa-00253526

\section{HAL Id: jpa-00253526 https://hal.science/jpa-00253526}

Submitted on 1 Jan 1994

HAL is a multi-disciplinary open access archive for the deposit and dissemination of scientific research documents, whether they are published or not. The documents may come from teaching and research institutions in France or abroad, or from public or private research centers.
L'archive ouverte pluridisciplinaire HAL, est destinée au dépôt et à la diffusion de documents scientifiques de niveau recherche, publiés ou non, émanant des établissements d'enseignement et de recherche français ou étrangers, des laboratoires publics ou privés. 


\section{Kurchatov synchrotron radiation source}

V.G. Stankevitch

Russian Research Centre "Kurchatov Institute", Moskow, Russia

Abstract: The status report on the Kurchatov Synchrotron Radiation Source (KSRS) is presented. Much attention is paid to the overview of KSRS injection complex commissioning. The summary of research directions is given.

\section{Introduction}

The construction of Kurchatov Synchrotron Radiation Source (KSRS) at Russian Research Centre "Kurchatov Institute" is coming to its end. KSRS consists of electron linac with energy $80 \mathrm{MeV}$, storage ring SIBERIA-1 -- booster with energy $450 \mathrm{MeV}$ (this little ring is simultaneously used as SR-source in VUV region), storage ring SIBERIA-2 with energy 2.5 GeV. The main parameters of booster SIBERIA-1 storage ring are presented in Table 1.

Table 1

The main parameters of the SIBERIA-1 storage ring

Energy [MeV] $\quad 450$

Current $[\mathrm{mA}]$

Bending radius $[\mathrm{cm}]$

Emittance E [cm rad] $\quad 8.8 \times 10^{-5}$

Bunch length $[\mathrm{cm}]$

Lifetime [h] 4

$\mathrm{Rf}$ frequency $[\mathrm{MHz}]$

$\mathrm{Rf}$ harmonic number 1

The electron transport line transfers the electron beam from SIBERIA-1 to the SIBERIA-2 storage ring. Table 2 presents the major characteristics of SIBERIA-2 storage ring.

Table 2

The main parameters of the SIBERIA-2 storage ring

$\begin{array}{ll}\text { Energy [GeV] } & 2.5 \\ \text { Orbit circumference [m] } & 124.13 \\ \text { No. of dipoles } & 24 \\ \text { Magnetic field in bending magnets [T] } & 0.425,1.7 \\ \text { Bending radii [cm] } & 1962.16,490.54 \\ \text { No. of } 3 \text { m long sections }(\eta=0) & 6 \\ \text { No. of 3.16 m long sections }(\eta \neq 0) & 6 \\ \text { Horizontal emittance } \mathrm{E}_{\mathrm{x}}[\mathrm{cm} \mathrm{rad}] & 7.65 \times 10^{-6} \\ \text { Revolution frequency }[\mathrm{MHz}] & 2.4152\end{array}$




\begin{tabular}{|c|c|}
\hline Rf harmonic number & 75 \\
\hline Rf frequency [MHz] & 181.14 \\
\hline \multicolumn{2}{|l|}{ Current $[\mathrm{mA}]$} \\
\hline single bunch mode of operation & 100 \\
\hline multibunch mode of operation & 300 \\
\hline Energy aperture & \pm 0.02 \\
\hline $\begin{array}{l}\text { Lifetime (single-bunch mode of operation, } \\
\mathrm{I}=100 \mathrm{~mA} \text { and coupling factor } \mathrm{k}=0.2 \text {, due to } \\
\text { the Touschek effect }[\mathrm{h}]\end{array}$ & 10 \\
\hline Bunch length $(\mathrm{V}=1800 \mathrm{kV})[\mathrm{cm}]$ & 4.4 \\
\hline
\end{tabular}

The building housing the SIBERIA dedicated synchrotron radiation source consists of two parts with independent bases (to minimize the vibrational influences ): an experimental hall where all accelerators, RF systems and experimental stations are located, and the technological part,where all engineering systems are located. The experimental hall has an area of $2700 \mathrm{~m}^{2}$. By now the expanding

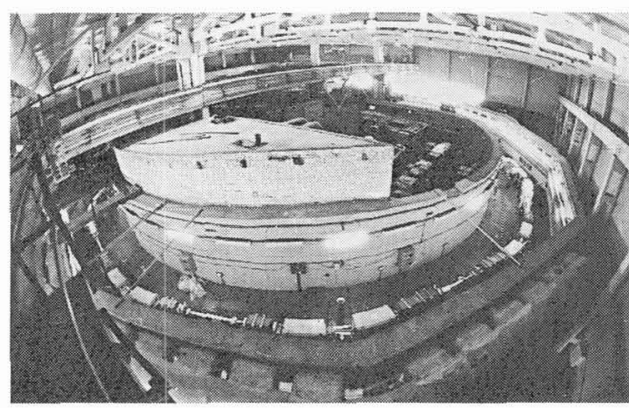

Fig. 1 SIBERIA-2. General view of experimental hall is planning.

The dedicated SR facility had been designed and constructed by the Institute of Nuclear Physics of the Siberian Division of the Russian Academy of Science. Mounting, commissioning and investigation to get project parameters are being fulfilled by both Institutions.

\section{Commissioning of the KSRS injection complex}

The injection complex of Kurchatov Synchrotron Radiation Source consists of linac and SIBERIA-1 booster ring connected by the electron transport line. Linac structure had been chosen according to Refs. 3,4 Designed linac parameters are the following: - energy $80-100$ $\mathrm{MeV}$, energy spread $-1 \%$, pulse current $-200 \mathrm{~mA}$, pulse duration $-15 \mathrm{~ns}$, transverse emittance $-0.1 \mathrm{mrad}^{*} \mathrm{~cm}$, repetition frequency $-1 \mathrm{pulse} / \mathrm{sec}$. Accelerator structure is fulfilled DAW type [5] with next parameters: wave type - TM-02, shunt impedance - $92 \mathrm{MOhm} / \mathrm{m}$, frequency $-2795.7 \mathrm{MHz}$, quaity 27000 , characteristic impedance $-3.4 \mathrm{kOhm} / \mathrm{m}$, length $-6.1 \mathrm{~m}$. Linac has no buncher and continuous electron beam with energy $40 \mathrm{KeV}$ and duration $15 \mathrm{~ns}$ is injected by diode electron gun to the accelerating structure. Input hole has high transparent grid. There exist vertical and horizontal correctors and focusing solenoid lens. The linac RF power supply consists of a klystron generator connected to accelerating structure by means of a $90 * 45 \mathrm{~mm} * \mathrm{~mm}$ rectangle waveguide. Klystron parameters are the following: pulse power up to $18 \mathrm{MW}$, repetition frequency - up to $100 \mathrm{~Hz}$, pulse duration -8 mcs, jitter on the top

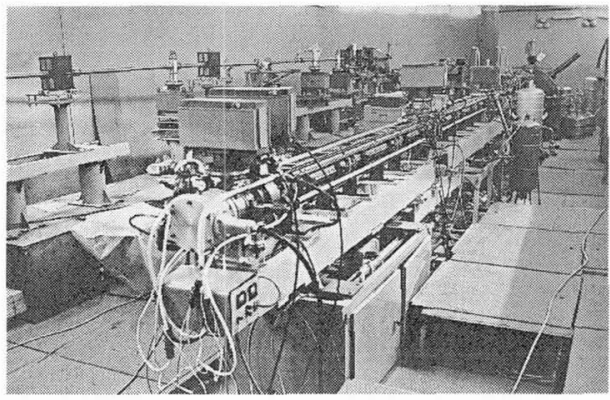

Fig.2. Perspective view of electron linac $\mathrm{E}=80 \mathrm{MeV}$ 
- $0.4 \%$, front duration - 2 mcs. Monitoring and location system of RF-breakdowns inside power supply waveguide and accelerating structure of electron linac was constructed.

By now we get power of $8 \mathrm{MW}$. At power level of $6.5 \mathrm{MW}$ linac gives electron beam with energy $70 \mathrm{MeV}$. electron current reaches $300 \mathrm{~mA}$ with energy spread $15 \%$.

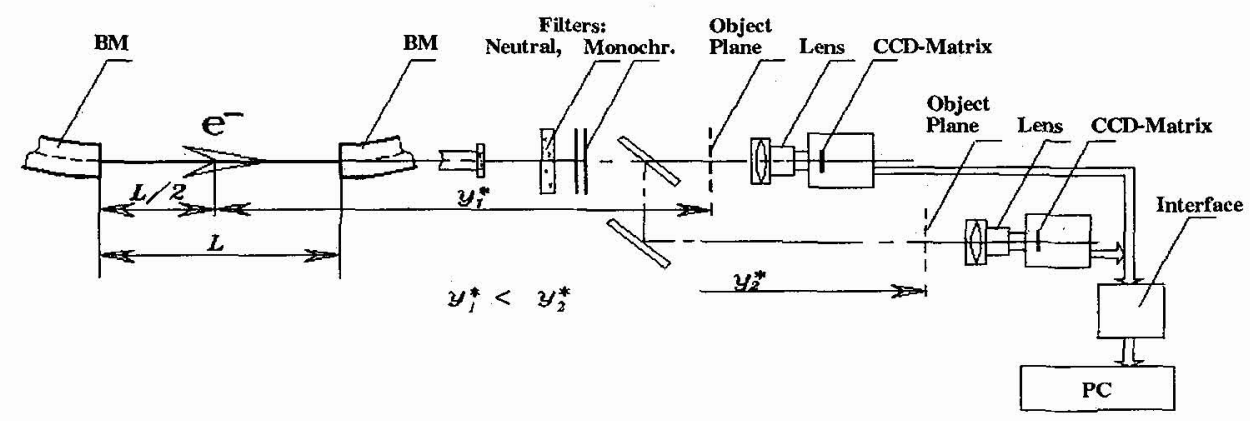

Fig.3 Equipment for registration of the ER intensity distributions.

In summer-93 linac and the little storage ring had been commissioning and they already have some milliamps and $450 \mathrm{MeV}$ of stored electron current in the little ring. Edge Radiation based system for measurement of horizontal and vertical angular divergences and transversal sizes, effective emittances, position and energy of electron beam was installed on the Siberia-1 storage ring (Fig.3). With the system, electron beam parameters are numerically determined from registered intensity distribution of visible range radiation emitted at bending magnet edges and at elements of electron beam optics (Fig.4). Currently, the system is adjusted to provide real-time control of the Siberia- 1 beam. The analogous equipment for the Siberia-2 ring is under construction.
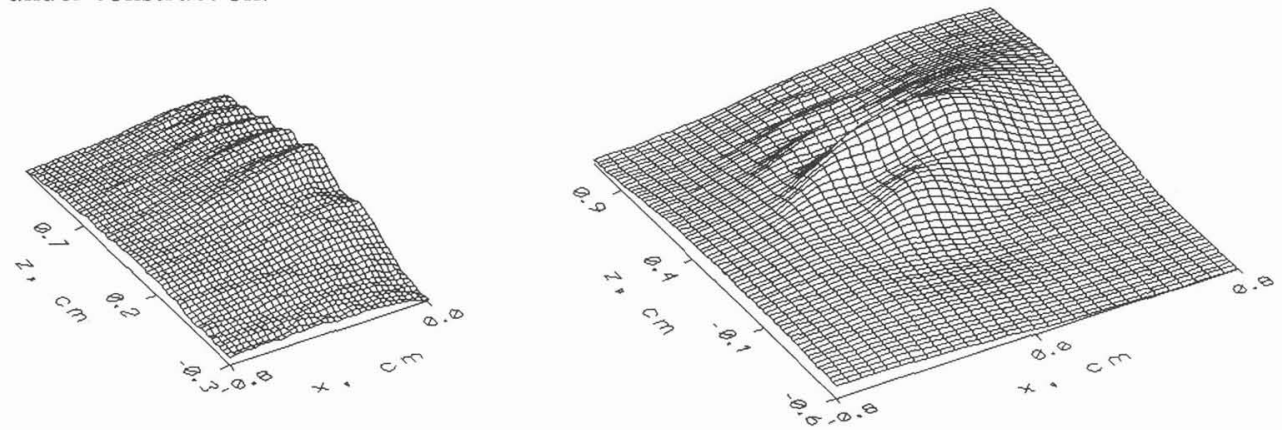

Fig.4 ER intensity distributions in object plane: experimental data (left) and corresponding best-fit over electron beam parameters (right).

Now the SIBERIA-1 storage ring has already gotten parameters permitting to use it as a VUV source. The construction of VUV experimental hall inside the big storage ring is nearly finished and in near future we will begin the establishing of VUV experimental stations. December 23, 1993, the SIBERIA-2 big ring magnet system and vacuum chamber had been mounted and now initial vacuum conditions had been achieved in it. One of two big accelerating cavities 
had been installed too. Three X-ray beam lines for SIBERIA-2 are now under construction. We hope that the first SR beam from SIBERIA -2 ring will be at the end of 1994.

The multipole superconducting wiggler is being designed in Kurchatov Synchrotron Radiation Centre. Its parameters are the following: period length $130 \mathrm{~mm}$, number of periods 11.5 , vertical magnetic gap $34 \mathrm{~mm}$, magnetic field amplitude $3.6 \mathrm{~T}$, critical wavelength $0.83 \mathrm{~A}$, full SR power $8 \mathrm{~kW}$ [6]. The calculations of the wiggler magnetic field influence on the beam dynamics were carried out. These calculations showed that the frequency shifts of the horizontal and vertical oscillations caused by the wiggler switching on are equal to 0.02 and +0.06 respectively. These shifts can be compensated by the

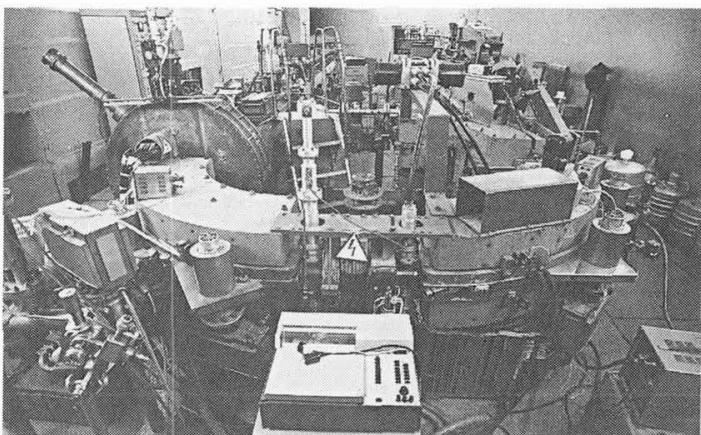

Fig. 5 General view of booster and SR source in VUV bandlittle storage ring SIBERIA - 1. straight section quadrupole lens magnetic field changing. Calculations show that switching on will not lead to the considerable dynamic aperture decrease.

Nowadays the model winding made of $\mathrm{NbTi}$ superconductor in $\mathrm{Cu}$ matrix of plane oval form and the fabrication of $\mathrm{Nb} \mathrm{Sn}$ wire of $1 \mathrm{~mm}$ diam. is near to finish.

\section{Research directions}

Being considered as user-oriented from the very beginning, KSRS design has incorporated as fully as possible the future user's specifications. Now the experiment proposals are the following :

\section{X - ray band.}

1.1 Semiconductor crystal structural changes research. It is intended to make use of Xray standing waves and secondary radiation angular dependence.

1.2 Moessbauer station.

1.3 EXAFS station.

1.4 Chemical shifts in X-ray emission lines. It is proposed to clarify the feasibility of determining the heavy atom chemical state in chemical compound, according to 8-10 $X$-ray line chemical shifts. Use will be made of elements from $Z=20$ (Ca) up to $Z-96$ (Cm).

1.5 Biopolymer structural transition research using small angle scattering with high time resolution:

1.6 X-ray polycrystal structure research. The multipurpose complex is intended to investigate phase transitions and material structure peculiarities at extreme temperatures and pressures (cryocrystals, HTSC, rare-earth alloys and compounds, actinides, caustic metals)

1.7 Refractive X-ray tomography. High angular resolution ( $<0.1 \mathrm{sec}$ of arc) technique is used to obtain images of biological object (blood vessels) without any contrast substances.

1.8 Precision measurement of electron densities in crystals in order to reveal minute details of chemical interaction.

1.9 Nonlinear resonance phenomena in SR scattering on perfect crystals. 
2. VUV - band

2.1 Investigation of electron structure of solids (optic methods, $5-50 \mathrm{eV}$ band).

2.2 Development and investigation of highly efficient crystal phosphors for application in image plate position sensitive detectors, VUV laser active media, medical phosphor screens and so on.

2.3 Solid state luminescence with X-ray excitation.

2.4 Excitation, migration and decay of electronic excitation in wide-band dielectrics and high temperatures superconductors.

2.5 Investigation of electron structure of metals, superconductors and semiconductors (photoelectron spectroscopy)

\section{Miscellaneous}

3.1 Photonuclear reaction research using polarized photons with energy about $100 \mathrm{MeV}$.

3.2 Electron and photon beam diagnostic.

All spectrometers are almost finished. The project work has begun to design the new experimental hall around the big storage ring. The number of Russian institutes which take part in scientific program is 14 .

\section{References}

1. V.V.Anashin et al,, Nucl. Instr. and Meth. A282 (1989) 369

2. A.N.Artemiev et al., Nucl. Instr. and Meth. A308 (1991) 61

3. M.M.Karliner, O.A.Nezhevenko, B.M.Fomel, V.P.Yackovlev, Preprint 86-146. Institute of Nuclear Physics, Novosibirsk , 1987

4.M.M.Karliner,O.A.Nezhevenko,G.N.Ostreiko,B.Z.Persov, S.I.Ruvinski,G.N.Serdobintsev, E.N.Sheimerdenov,V.G.Vescherevich, V.P.Yackovlev Proc. of the EPAC, Rome, 1988, p 602-604.

5. V.G.Andreev Zhurnal technicheskoi fiziki t.1 s.788

6. A.N. Artemiev, A.V Barkov, A.I. Chechin, A.V Dudarev, Yu.V. Krylov, N.V.Smolyakov , Nucl. Instr. and Meth A308 (1991) 77-79 